\title{
in the press
}

\section{Iron man's impact}

When a Nazi team on expedition in Tibet snatched a Buddhist statue around 1939, they may have chosen the piece for a 3,000-yearold sun symbol on its belly that, in a later form, would become known as the swastika. But the statue's more appropriate claim to fame has only now come to light: it was carved from a meteorite that landed on Earth more than 10,000 years ago (Meteorit. Planet. Sci. 47, 1491-1501; 2012).

Knowledge of its whereabouts in the decades after the Nazis seized the roughly 1,000 -year-old statue is fuzzy. But in 2007, it was in the hands of a collector. When he died, his son sold it at auction in Munich, and the new owner decided to seek help in figuring out what the strange-looking figure was made from and whether it was carved or cast. The owner found his way to Germany's Stuttgart University, where Elmar Buchner, lead author on the paper, had a look.

Buchner specializes in studying meteorites, and the minute he saw the statue, he was confident of the material's origin. He was anxious to confirm his suspicion, but the owner wasn't interested in allowing any destructive sampling of the statue, which is thought to represent the Buddhist god Vaisravana.

He did, however, give Buchner and his colleagues a small sliver of material to work with. The researchers ran limited analyses to look at concentrations of metals such

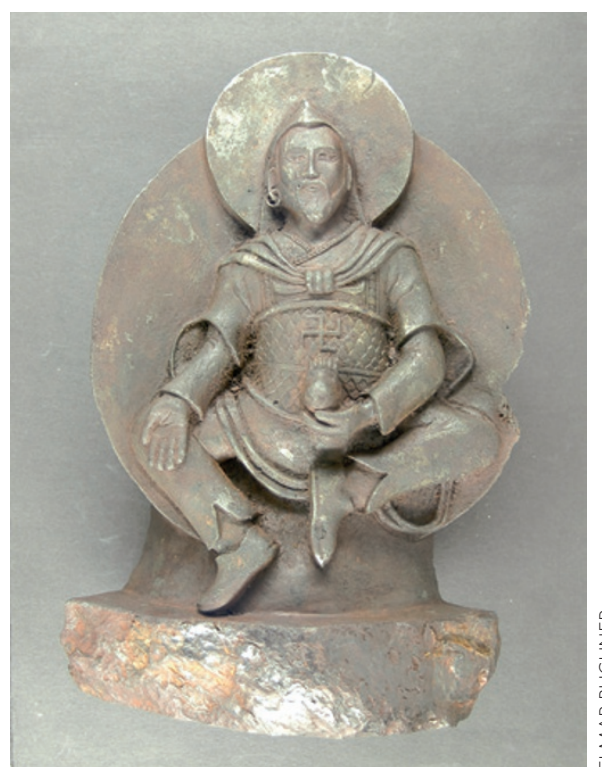

due to entry heating. Nobody would want to deface the statue's front, where the altered surface material had been carved away. This would leave only the option of sampling from the base, which was a meteorite surface and thus required deeper sampling.

The owner would not allow drilling, but he did decide to resell his purchase that had now become more valuable. One of the authors (the team is not disclosing which one) decided to buy the statue himself. So, the researchers were able to remove a $1.5-\mathrm{cm}$-deep disc from the statue's base for full analysis.

Percentages of metals like nickel and cobalt vary widely between meteorites, leading to a unique signature for each object. Once the team fed the statue's chemical data into a meteorite database at the University of Vienna, they discovered that the material was a nearly perfect match to the Chinga meteorite, which fell to Earth in the Siberia-Mongolia region an estimated 10,000-20,000 years ago. Hundreds of pieces of Chinga had been previously collected and analysed.

It was an amazing and satisfying geochemical conclusion - even though we still do not know who carved the statue, or exactly when.

Mark Schrope is a freelance writer and editor based in Florida.

\section{The journalist's take}

A massive meteorite falling from the prehistoric sky. A Nazi seizure and a mysterious disappearance into the world of private artefact collectors. A surprise resurfacing, chemical sleuthing and a remarkable conclusion. It is difficult to imagine a geochemical tale better suited to grabbing the attention of a less-thangeochemically-minded public than the results of the 'iron man' statue analyses.

Media outlets around the world covered the findings. It is, of course, the background story rather than the science that made this research paper so popular, but at its heart it is still a science tale. Whenever research taps into interesting history that the average person can relate to or be in awe of, there is great potential for grabbing public attention — and hence media interest.

Just how much history is needed to cross the boundary between attention and a lack thereof is difficult to specify. This particular story offers an interesting case study within a case study: after the team did its initial analyses and concluded the statue was carved from a meteorite, National Geographic Germany covered the result. Buchner did not expect any attention from the English press, but he did assume that the German media would show interest. They didn't.

But when the team did the more complete analyses, made the Chinga discovery and had it peer reviewed, the story took off. The team fielded press inquiries from six continents and saw their work mentioned in countless media outlets - though some stories focused much more on cultural elements barely touched on in the paper, such as why the Nazis grabbed the statue, than on the science.
The journal publisher and the scientists' institutions issued press releases on the paper, which probably explains much of the extra attention. But it is likely that even with press releases the story wouldn't have been nearly as popular back in 2007 without that added awe-inspiring Chinga element.

The tale of the Buddhist statue is especially well suited for attention, but other types of geoscience research can also offer strong cultural ties, such as work at the harbour of ancient Troy that yielded geological results consistent with Homer's Iliad (Geology 31, 163-166; 2003). Journal papers often skim past the cultural background. Those looking to engage a broader audience, or who simply appreciate the value of placing their work in fuller context, might give culture a bit more consideration when publishing. 